\title{
Genes, Interactions, and the Development of Behavior
}

\author{
Timothy D. Johnston \\ University of North Carolina at Greensboro
}

\author{
Laura Edwards \\ Wilson County Public Schools
}

\begin{abstract}
Explaining how genes influence behavior is important to many branches of psychology, including development, behavior genetics, and evolutionary psychology. Presented here is a developmental model linking the immediate consequence of gene activity (transcription of messenger RNA molecules from DNA sequences) to behavior through multiple molecular, cellular, and physiological levels. The model provides a level of detail appropriate to theories of behavioral development that recognizes the molecular level of gene action, dispensing with the metaphorical use of such terms as blueprints, plans, or constraints that has obscured much previous discussion. Special attention is paid to the possible role of immediate-early genes in initiating developmental responses to experience, adding specificity to the claim that neither genes nor experience act alone to shape development.
\end{abstract}

The question of how genes affect behavior has been a longstanding focus of both controversy and research within the behavioral and social sciences. It is most directly of concern to the study of behavioral development (Gottlieb, 1998; Wahlsten, 1999) but is also important for behavior genetics (McClearn, Plomin, GoraMaslak, \& Crabbe, 1991; Plomin \& Rutter, 1998; Turkheimer, 1998) and evolutionary psychology (Buss, 1994; Lloyd, 1999). Although no one today seriously doubts that behavior is influenced in some way by genetic constitution, a general understanding of the mechanisms by which genes exert their influence is still far away. The immediate effect of genes is to specify, through the intermediate stage of messenger RNA (mRNA) synthesis, the polypeptide sequences of various proteins, including those involved in brain structure and function and thus presumably in the organization of behavior. It is, however, a very long step from polypeptide sequences to behavior - a step, moreover, that covers much incompletely understood territory. The aim of this article is to provide a map of that territory, in the form of a model that incorporates genetic influences into a conceptually rigorous account of the development of behavior.

This article focuses on the development of behavior. However, genetic activity is involved not only in the developmental transi-

Timothy D. Johnston, Department of Psychology, University of North Carolina at Greensboro; Laura Edwards, Wilson County Public Schools, North Carolina.

The model described in this article was originally presented at the annual meeting of the International Society of Developmental Psychobiology, Alexandria, Virginia, November 1993, and in a modified form at the Third International Institute on Developmental Science, Chapel Hill, North Carolina, May 2000.

We thank Patrick Bateson, Gilbert Gottlieb, Susan Oyama, and Douglas Wahlsten for helpful comments on earlier versions of this article and Jacquelyn Gray, Julian Lombardi, and Jay Rosenblatt for various stimulating discussions of the ideas.

Correspondence concerning this article should be addressed to Timothy D. Johnston, Department of Psychology, University of North Carolina at Greensboro, P.O. Box 26164, Greensboro, North Carolina 27402-6164. E-mail: johnston@uncg.edu tions between conception and maturity but also in the processes of learning and behavioral plasticity that occur throughout the life span (Robertson, 1992; Tischmeyer \& Grimm, 1999). Any account of genetic influences on behavior must include an analysis of the different "causal pathway[s] through which the gene influences the phenotype" (McClearn, et al., 1991, p. 223). Although the techniques of behavioral genetic analysis permit the identification of individual genes with significant effects on behavior (Wahlsten, 1999), understanding how genes influence behavior requires an analysis of the various processes underlying behavioral changes (Gottlieb, 1995).

Our analysis extends ideas proposed in earlier articles (Johnston, 1987, 1988) and builds on work done by other developmental theorists working within a framework usually identified as interactionism or developmental systems theory. From this perspective, genes appear as one among many contributors to a complex network of interactions, involving molecular, cellular, physiological, behavioral, and environmental components (Bateson \& Martin, 2000; Gottlieb, 1996). The network is a system with multiple bidirectional effects (see Gray, 1992; Griffiths \& Gray, 1994; Oyama, 2000), not one in which genes directly specify behavior or some behavioral surrogate, such as a plan or blueprint. The model presented here situates the genes within such a network, offering a clear view of the relationships between genetic and other influences on the development of behavior.

\section{A Model for the Development of Behavior}

Figure 1 presents a very simple view of the relationships among three classes of factors that influence the development of behavior. Sensory stimulation refers to any influence that acts through the developing animal's sense organs and is processed by its nervous system, including all the effects of learning and of experience more generally construed. Physical influences include all other environmental effects (both physical and chemical), including diet, temperature, $\mathrm{pH}$, salinity, gravity, and the mechanical stresses exerted during movement. Some components of the environment provide both physical influences and sensory stimulation (for example, 


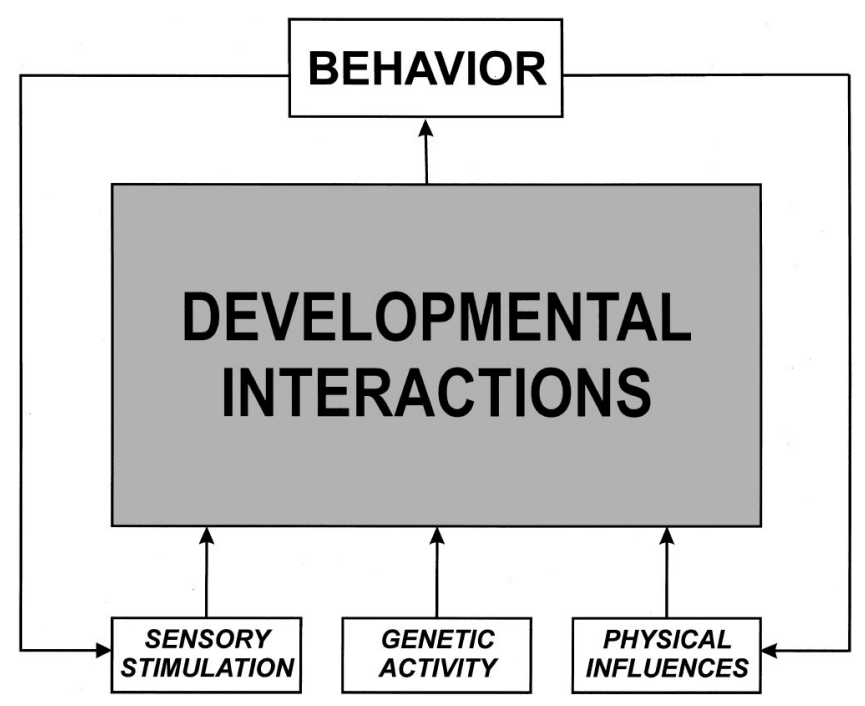

Figure 1. Starting point for an analysis of behavioral development, identifying the three classes of input as sensory stimulation (environmental influences that are processed by the developing animal's nervous system), physical influences (all other environmental effects), and genetic activity. Both sensory stimulation and physical influences are directly affected by behavior; the effect of behavior on genetic activity is indirect and is hidden in this diagram. The task of a developmental analysis is to unpack the developmental interactions implied by the shaded box.

food provides both direct chemical input to the body and a variety of gustatory, olfactory, and visual stimuli), whereas others provide only one of these. Genetic activity refers to the transcription of DNA that underlies the involvement of the genes both in protein synthesis and in the regulation of their own activity. These three classes of input interact (in ways yet to be specified) to produce behavior; the shaded box in Figure 1 represents these developmental interactions. As shown in Figure 1, behavior itself can directly change the nature of sensory stimulation and physicochemical influences; genetic activity is also influenced by behavior, but only through indirect pathways that are hidden in this figure.

Constructing the model of development requires "unpacking" the hidden complexity in the shaded box in Figure 1 to provide a clear understanding of what components of the organism and what relationships among them it conceals. This is done by analyzing the complex interactions implied by the box into successively simpler ones. However, in doing so, it is important to avoid introducing relationships that are not firmly anchored in the biological constitution of the developing organism, so as to avoid the implication that genes can act at a distance and all variants of what Oyama $(1985,2000)$ has called the "ghost-in-the-machine machine": blueprints, instructions, constraints, information, and so forth. This point is very important because the model must recognize that genes are biologically active molecules, not mysterious carriers of information or repositories of plans and blueprints. As pointed out by Johnston (1987) and Nijhout (1990), among others, such metaphorical discussion about genes has not provided much understanding of their contributions to development (see also Keller, 1994; Oyama, 2000; Pfaff, 1997).

Figure 2 shows a first stage in this unpacking, indicating that gene activity directly and reciprocally affects protein synthesis and that sensory stimulation directly and reciprocally affects patterned neural activity. The shaded box has shrunk, and neither of the new boxes contains hidden examples of action at a distance. It would, of course, be possible to unpack each of these boxes further, and for some purposes that may be necessary. However, by not unpacking them, the model claims that this is a sufficiently detailed account for capturing important general features of behavioral development and that the generality would not be significantly enhanced by further analysis. (That is, of course, an empirical claim that may need to be modified in the light of attempts to use the model to construct particular theories of behavioral development.)

Figure 3 shows the completely unpacked model of behavioral development. None of the relationships depicted by the arrows in Figures 1 and 2 have been deleted, although new relationships have been indicated by the addition of appropriate arrows. An arrow connecting one box $(x)$ to another box $(y)$ is to be interpreted as meaning, "The state of $x$ may affect the state of $y$." Time is not explicitly represented in Figure 3; a later section shows how to convert this representation of causal relationships into a representation that acknowledges the simultaneity and successiveness of developmental events.

\section{Some Properties of the Model}

The representation of development in Figure 3 is similar in spirit to other depictions, such as those of Gottlieb (1991, Figure 1) and Bateson (1996, Figure 1.1), but it extends them and explicates some important features of development as follows.

First, it includes both neural and nonneural components. Behavior requires not only patterns of neural activity but also nonneural structures and systems. Perhaps the most thoroughly studied ex-

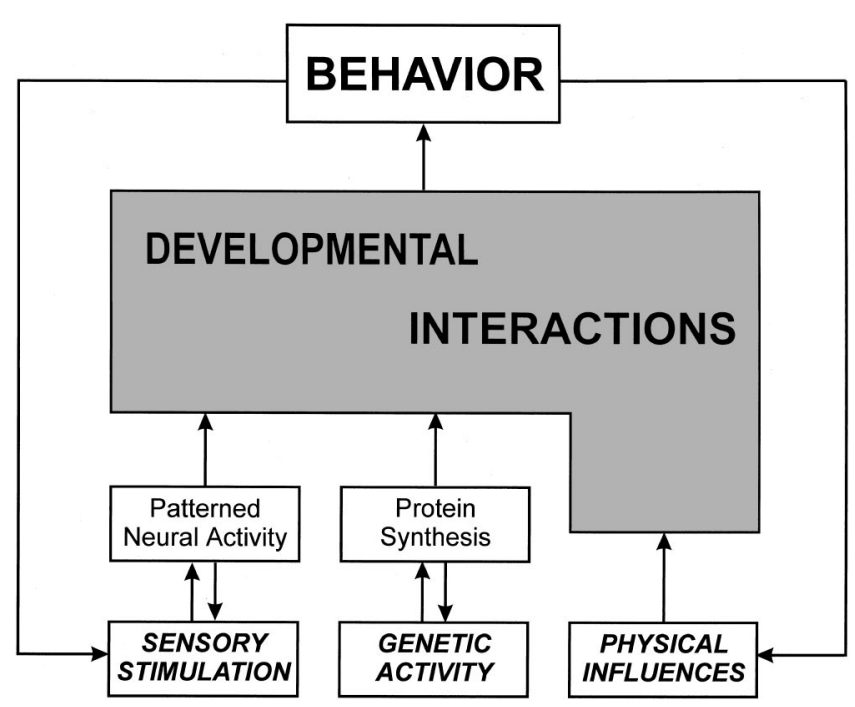

Figure 2. First stage in the analysis of development. The immediate effect of sensory stimulation is on patterns of activity in the nervous system. This effect may be reciprocal, as centrifugal influences (attention, orientation, and so forth) modulate the stimulation influencing the organism. The immediate effect of genetic activity is protein synthesis, which may also have reciprocal effects on genes. The effects of physical influences are not elaborated in this diagram. 


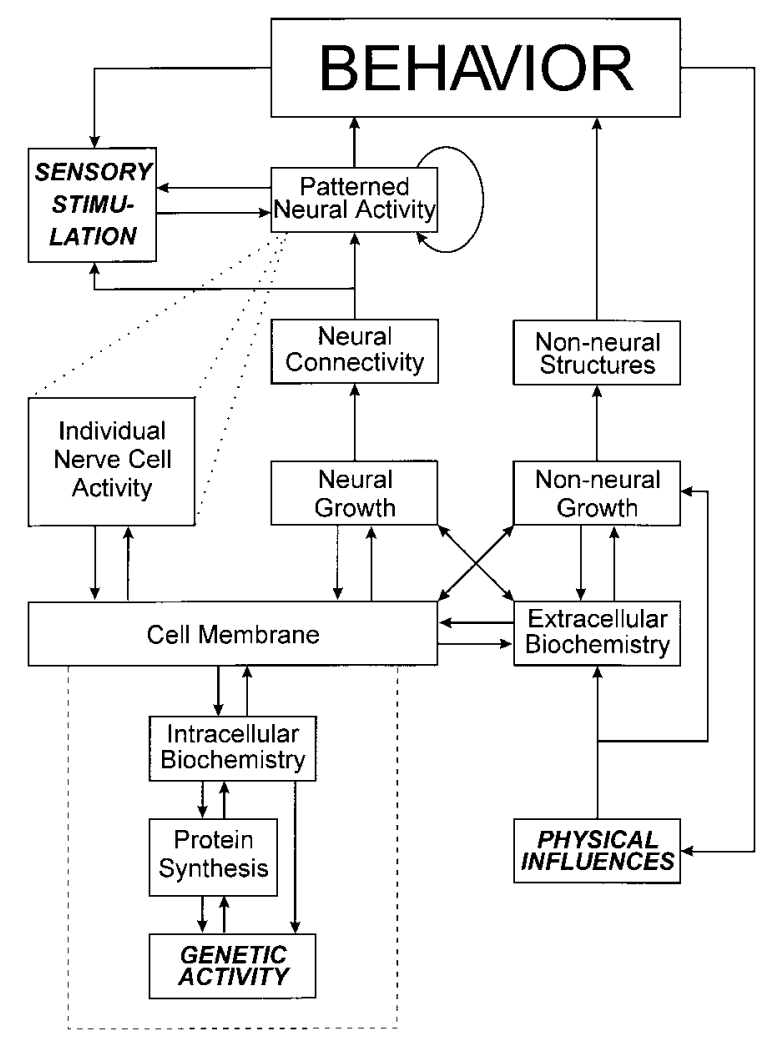

Figure 3. Completely unpacked model of behavioral development, showing all the interacting factors involved in the developmental construction of behavior and the interactions among them. The model includes both neural and nonneural elements, the latter encompassing such influences as hormones (which constitute part of the extracellular biochemistry), bones, muscles, feathers, and so forth. Sensory stimulation is shown to be influenced not only by behavior (as the animal moves about in its environment, both producing and modifying the stimulation it receives) but also by the connectivity of its nervous system (which partly determines its sensitivity to sources of stimulation) and by the current state of neural activity. The elliptical arrow depicts the effects of spontaneous neural activity. All enduring experiential effects on development, which have their immediate impact on patterns of neural activity, act by modifying events at the cellular level, including patterns of genetic activity. Note that there is no direct connection between genetic activity and behavior; all genetic effects on behavior are mediated through the cell membrane and subsequent interactions among cells and neural networks. Solid lines with arrows represent causal relationships between interacting factors. Dotted lines connecting patterned neural activity to individual nerve cell activity indicate that the latter is nested within the former, the relationship between the two is not causal.

amples of nonneural contributions to behavioral development involve the effects of hormones (e.g., Arnold \& Breedlove, 1985; Collaer \& Hines, 1995); however, development of behavior also involves bones, muscles, horns, feathers, and other structures, and all of these components need to be taken into account. The importance of doing so is particularly clearly illustrated in Thelen's (1995) and Thelen, Kelso, and Fogel's (1987) analyses of the development of infant locomotion, in which gross morphological changes play a critical role in explaining the development of locomotor patterns.
Second, the immediate consequences of genetic activity are confined to the cell. Genetic effects on behavioral development must take into account the various interactions that follow from protein synthesis and its consequences for events at the cell membrane, interactions among cells, and so forth. The model treats genes as an integral part of the developing system (Gottlieb, 1995), rather than placing them outside the system, and shows that genes influence behavior indirectly, not directly. This model does not necessarily preclude defining relationships between genetic activity and behavior unless all the intermediate steps implied in the diagram can be specified. When a particular gene has been implicated in the development of some behavior, for example, the model would accommodate the identification of various roles that the gene's activity might play in development. Such a taxonomy of genetic roles would be conceptually similar to that proposed by Gottlieb (1976) for the contributions of experience to development; the latter has been a useful model despite the fact that it does not specify all the processes that intervene between the experience and the behavior (cf. Gottlieb, 1991, 1995). For example, in a review of the effects of single-gene mutations on the development of touch receptors in the nematode Caenorhabditis elegans, Chalfie (1993) proposed four developmental roles (generation, specification, function, and maintenance) for the 18 genes that have been implicated so far in touch receptor development. Although Chalfie's work deals with anatomical rather than behavioral development, similar taxonomies might be proposed for behavioral mutations (see Schaffner, 1998). Our model has the advantage that it provides an explicit representation of the intervening interactions implied by such a taxonomy, even though these interactions may not necessarily always be specified. Thus, it indicates the kinds of developmental questions raised by findings that might otherwise be interpreted as evidence of a direct link between genes and behavior.

Third, when experience has more than a very transient effect on behavior, the effect is almost certainly mediated through changes in genetic activity. Indeed, the model implies that all instances in which experience has been shown to affect behavioral development must involve some change in genetic activity. Developmental theorists have frequently argued that there can be no genetic effects on behavior independent of the environment, and it can be added that there are probably no environmental effects on behavior independent of genetic activity. This statement, of course, has been made before (e.g., Bateson, 1983, 1987; Gottlieb, 1998), but the model helps to make the statement more precise by showing the pathway by which experience activates genes through the agency of neural activity. There is considerable evidence to suggest that the initial stage in this process involves a class of genes known as immediate-early genes (IEGs; Arenander \& Herschman, 1993; Morgan \& Curran, 1989, 1991; Robertson, 1992). The possible role of IEGs in behavioral development is further discussed in a later section.

Fourth, the model recognizes that nervous system activity needs to be considered at two levels-in terms of patterns of neural activity, often involving networks of cells in widely separated anatomical regions, and in terms of the activity of individual nerve cells, within which the genes are located. The dotted lines connecting these two boxes in Figure 3 indicate that the activity of individual cells is nested within the patterns of activity of cell networks. Individual cell activity neither causes nor is caused by 
the patterns of activity in cell networks; rather, these are two levels at which neural activity may be analyzed. Recognizing the necessity for such dual levels of analysis does not mean that an account of genetic activity must be given individual cell by individual cell. Instead, ways of describing the developing nervous system both in terms of populations of cells with similar patterns of genetic activity and in terms of networks of cells that participate in the control of behavior must be found. For example, Brennan, Hancock, and Keverne (1992) have shown that the IEGs c-fos and zif-268 (but not the IEG c-jun) show distinct patterns of both transient induction and more persistent induction in the accessory olfactory bulb (AOB) of the female mouse immediately after mating. The induction of c-fos is seen only in the granule cells of the AOB, whereas zif-268 induction occurs in both the granule and the mitral cells. The AOB is known to be involved in changes in female olfactory responsiveness to male pheromones following mating, and the differential patterns of gene expression in these two cell types indicate the complexity of the relationships that are likely to exist between neural networks and genetic activity in the AOB.

\section{Successiveness and Simultaneity in Development}

As depicted in Figure 3, the model includes no explicit representation of time. Time is clearly an important component of developmental explanations, and any plausible model of development must be able to represent change over time. Each box in Figure 3 can be thought of as containing a description of the factor that it names at a particular point in development. Thus, behavior may describe the locomotor capabilities of an 18-month-old human infant; neural growth may describe a particular mechanism of cell-cell recognition in the early development of the cerebellum; and genetic activity may describe the transcription of a particular stretch of DNA in a specific population of cells in the substantia nigra. These descriptions may be given at any desired level of detail and may be expressed in any form (verbal, pictorial, or mathematical) appropriate to the developmental inquiry being pursued.

If one were to focus on a particular box as development proceeds, the description it contains would change; the change might be slow, encompassing many days or weeks, or it might be very fast, covering only a few seconds. Again, the description depends on the developmental dynamics of the factor being studied (neural growth occurs quite slowly, whereas changes in the cell membrane may occupy only a few milliseconds) and the degree of detail being sought in the account. As development proceeded, different influences among those represented by arrows entering the box would be seen to come into play; at one point, neural growth might be influenced by some nonneural factor, whereas at another, it might be influenced by changes at the cell membrane brought about by a particular pattern of individual cell activity. The depiction in Figure 3 can thus be thought of as a template for a single frame in a "movie" of development, with all of the possible boxes and arrows indicated but with no specification of which arrows influence which boxes at a particular time. This template defines the set of elements and interactions among them that are available for explaining instances of behavioral development but does not represent the successive and simultaneous events that underlie any particular instance.
One way to add the temporal dimension is by projecting the two-dimensional representation in Figure 3 into a third dimension, representing time. The three-dimensional representation would then have arrows connecting boxes (now three-dimensional) only at the points in time at which those influences actually occur. Figure 4 shows such a representation for part of the model, representing just a few of the 14 boxes as three-dimensional objects stretching back into the page. The curved arrows show some of the points at which a change in one factor causes a change in another.

This pictorial representation explicitly adds a time dimension to the model in Figure 3, but it will not accommodate much detail without becoming hopelessly complicated. To provide a more detailed representation of the temporal relationships involved, Figure 4 can be recast in a different form (Figure 5). Here, each row represents one of the 14 factors shown in Figure 3. The numbered boxes in each row represent descriptions of the changing states of the relevant factor over time; again, the descriptions can be given in any convenient form and with any desired degree of detail. Causal relationships (whether demonstrated or hypothetical) are indicated by using an arrow to connect a box on one line to a box on another line. (The numbers within the boxes are merely arbitrary labels, arranged in approximately chronological order.)

The first line of Figure 5 ("Behavior") contains a series of descriptions corresponding to the changes observed in behavior between time $t_{i}$ and time $t_{n}$. In this case, the behavior undergoes two changes during the period under consideration; these are represented by three boxes with different degrees of shading. If the example depicted were the development of song in a songbird, the first transition might be that between the nestling stage and the initial appearance of immature song (subsong), and the second transition might represent the crystallization of full song in adult-

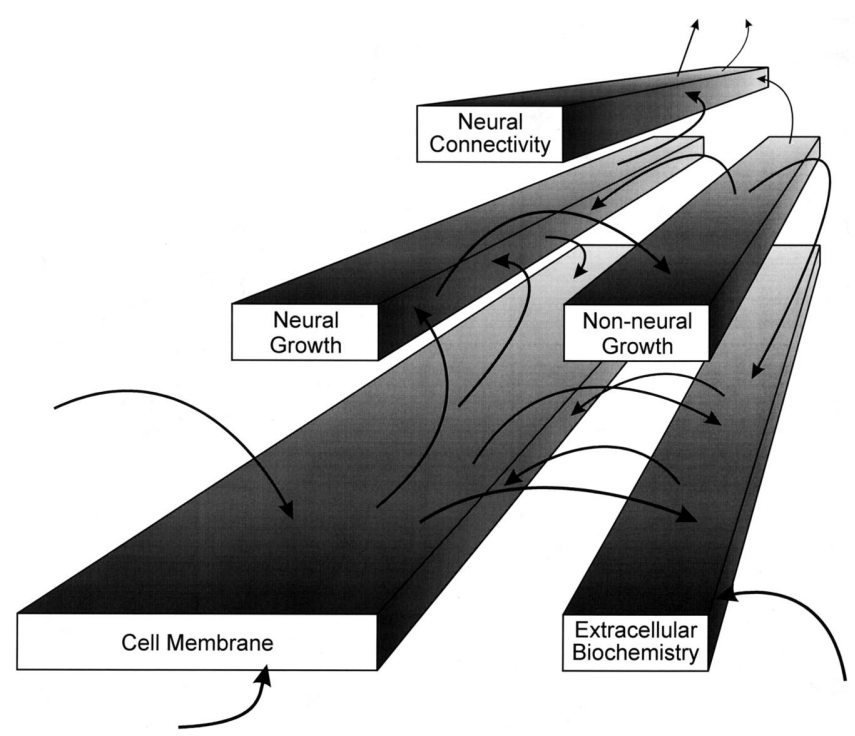

Figure 4. Addition of a temporal dimension to the model by extension of the boxes representing interacting factors into a third dimension, stretching back into the page and representing time. Curved arrows represent interactions between the factors at particular times. Such a depiction illustrates the successiveness and simultaneity of developmental interactions but quickly becomes too complex to be analytically useful. 


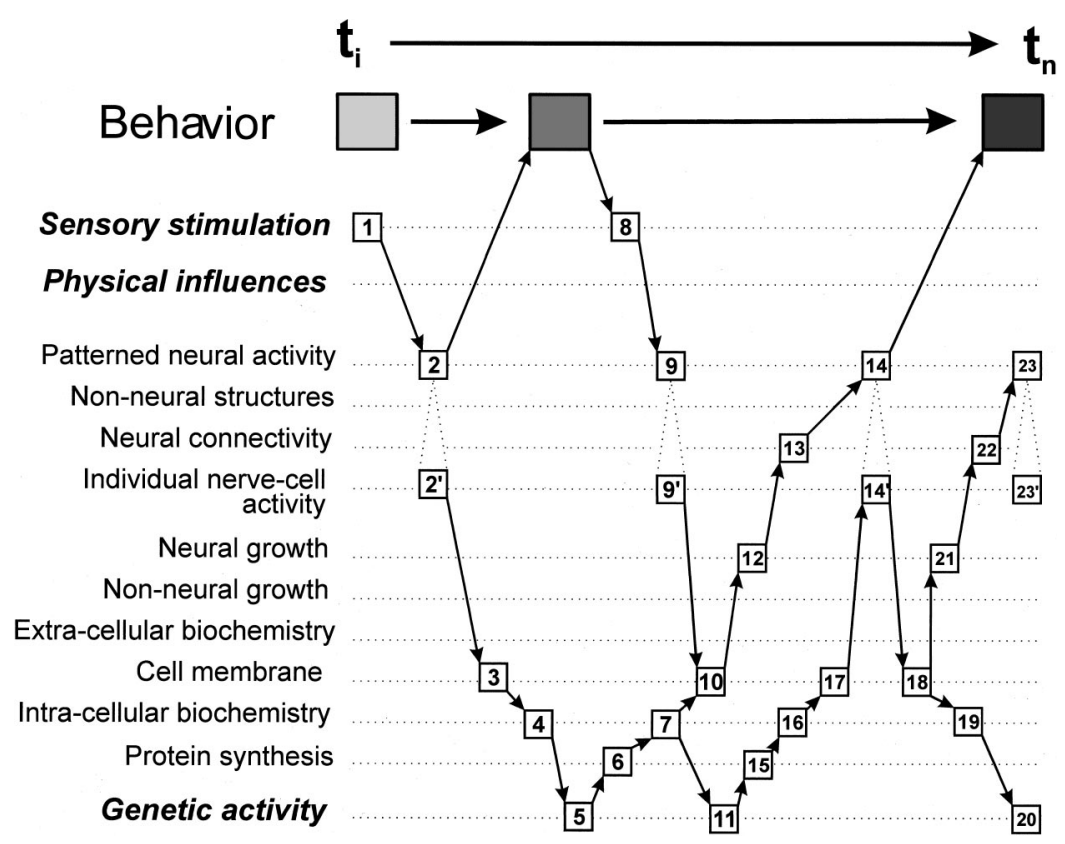

Figure 5. Alternative representation of the simultaneous and successive interactions among factors in development, shown for a hypothetical example in which some behavior goes through two developmental changes over a span of time. The diagram should be read from left to right and from top to bottom, more or less following the sequence of numbered boxes. Each of the rows corresponds to one of the factors shown in Figure 3. Arrows represent hypothetical interactions that are responsible (according to the particular theory being depicted) for the change in behavior from time $i\left(t_{i}\right)$ to time $n\left(t_{n}\right)$. Only relationships sanctioned by the underlying model of development (Figure 3) may be entered in the form of arrows on this diagram. As in Figure 3, the relationship between patterned neural activity and individual nerve cell activity $\left(2-2^{\prime}, 9-9^{\prime}\right.$, and so forth) is one of different levels of analysis, not causality. This pictorial symbolism allows the depiction of both diverging and converging causal relationships among multiple interacting factors (note boxes $2-2^{\prime}, 7,10$, and 18). Boxes 18 through 23 illustrate the cascading effects of developmental interactions beyond the specific behavioral change under analysis.

hood (Marler, 1990; Nottebohm, 1989). The network of arrows and boxes in the other lines in Figure 5 represents a theory of how these changes in behavior are brought about by interactions among the various factors depicted in Figure 3. The way in which the network is constructed is constrained by the possible elements and interactions sanctioned by the underlying model of development (Figure 3). Arrows cannot simply be added without justifying them in terms of the model. Of course, if evidence for the existence of interactions that do violate the underlying model were found, then it would be necessary to reevaluate the model.

The entire diagram represents a theory of the developmental interactions underlying a particular (hypothetical) change in behavior. The pictorial formalism of the diagram allows the depiction of development as a cascade of both simultaneous and successive events, and it also represents the convergence and divergence of causal influences on development. Thus, for example, Figure 5 shows a change in cell membrane properties (10) that is jointly influenced by the convergence of intracellular events resulting from prior genetic activity (7 to 10) and of individual nerve cell activity brought about by an earlier change in behavior ( $9^{\prime}$ to 10$)$. Similarly, the change in intracellular biochemistry (7) is shown to have effects both on properties of the cell membrane ( 7 to 10 ) and on subsequent genetic activity (7 to 11$)$.
As it stands, the depiction in Figure 5 provides no account of how the various components of development change or of how one factor influences another. Such an account can be provided by writing descriptions of the interacting elements shown in the figure to specify how they interact to produce the observed changes in behavior. The figure represents these interactions as functions (arrows) that map the various elements (boxes) to one another. For example, the state of neural growth at time $t_{i}$ might map to neural connectivity at time $t_{i+1}$ according to some function that represents an understanding of the effects of neural growth on neural circuitry (12 to 13). Such a function might be very simple (e.g., the statement "increased growth produces greater connectivity") or might be very complex, amounting to a fully fledged theory of how neural growth creates particular patterns of connectivity in a particular brain region. Whatever functions are used, they must respect the interactions specified in the underlying model; that is, the theorist cannot arbitrarily write functions that require interactions not permitted by the model. It is possible that the particular interactions represented by a function have already been discovered, in which case the theory organizes existing knowledge. Alternatively, the function might imply the existence of interactions that would, if they occurred, generate the observed changes in behavior. In the latter case, the theory makes a prediction about the developing system that can be empirically investigated. 


\section{Genetic Contributions to Development}

Although the model presented here is intended to take into account all the various influences on the development of behavior, it was constructed primarily to explicate genetic contributions, because these in particular have proven so difficult to conceptualize. Even as more has been learned about how genes work, it has remained common to speak in highly deterministic language about their effect on behavior. For example, Wheeler et al. (1991) found that inserting a short length of Drosophila simulans DNA into the genome (specifically the per gene) of $D$. melanogaster changed the species-typical periodicity of male song from that of D. melanogaster to that of $D$. simulans. From the perspective of the model presented here, this finding raises interesting questions about the role of the per gene in the development of this species-typical behavior (see Hall, 1998). However, it does not allow one to conclude that the inserted DNA is "responsible for the speciesspecific courtship behavior instructions encoded within this clock [per] gene" (Wheeler et al., 1991, p. 1085; emphasis added). ${ }^{1}$ The preceding quotation is not at all atypical —numerous similar statements can be found in discussions about genetic contributions to development, whether in scientific or lay writings (see Johnston, 1987; Nelkin \& Lindee, 1995; Nijhout, 1990). For example, an article summarizing recent advances in DNA sequencing announces that, "The instructions for assembling every organism on the planet... are all specified in DNA sequences" (Lander \& Weinberg, 2000, p. 1777). Although such statements are usually excused as convenient shorthand for what "everyone knows" to be a very complex set of developmental interactions, that shorthand has been a persistent obstacle to clear thinking on this topic.

The model presented here does not attempt to specify every molecular and cellular detail of the complex interactions that intervene between genetic activity and the changes in behavior that constitute development, but it does provide a useful intermediate level of detail that captures that complexity while at the same time rendering it reasonably comprehensible. Thus, it shows genetic activity to be confined to the cell, requiring that any account of genetic influence on behavior offer at least a sketch of how that influence should be understood in terms of mechanisms such as changes in cell membrane (especially synaptic) properties, contact interactions among cells, and the resulting changes in neural circuitry.

Although the effects of experience have often been placed in opposition to genetic effects on development, it is becoming increasingly clear that experience influences behavior by activating genes in specific populations of cells. The first stage in such experience-dependent genetic activity appears to be the class of genes known as IEGs. IEG induction has been shown to be very closely and specifically linked to the onset of sensory stimulation (Morgan \& Curran, 1991). In a wide variety of central nervous system regions, sensory stimulation is followed, typically within 20 to $30 \mathrm{~min}$, by a wave of IEG induction that spreads transsynaptically in a manner predicted by the neural organization. Thus, for example, exposing rats to low-intensity sounds results in a tonotopic pattern of IEG transcription in the cochlear nucleus and other auditory structures (Ehret \& Fischer, 1991; Rouiller, Wan, Moret, \& Liang, 1992); similar findings have been obtained for cutaneous stimulation in the spinal cord (Williams, Evan, \& Hunt, 1990). Of special interest for the study of behavioral development are the numerous demonstrations of IEG expression following both exposure to and production of song in the brains of several species of songbirds (Jin \& Clayton, 1997; Kimpo \& Doupe, 1997; Mello, Nottebohm, \& Clayton, 1995; Mello, Vicario, \& Clayton, 1992; Nastiuk, Mello, George, \& Clayton, 1994). Thus, it might reasonably be proposed that IEG induction is involved in all responses by the nervous system to sensory stimulation, including instances of behavioral development that have been shown to depend on experience.

Most of the behaviorally relevant work on IEGs has involved adult animals, although some studies have been done with developing systems. For example, transcription of the IEG zif-268 increases rapidly between postnatal day 12 and postnatal day 21 in the visual systems of rat pups reared in normal illumination but shows little change in pups reared in the dark (Worley et al., 1990), and c-fos induction increases on exposure to a novel environment in the forebrains of 1- to 6-day-old chicks (Anokhin, Mileusnic, Shamakina, \& Rose, 1991). Other studies have implicated IEG induction in the early development of circadian rhythmicity $(\mathrm{Ru}-$ sak, Robertson, Wisden, \& Hunt, 1990; Rivkees, Weaver, \& Reppert, 1992) and in some of the cellular events involved in learning and the formation of memories (Dragunow, 1996; Lanahan \& Worley, 1998; Robertson, 1992; Tischmeyer \& Grimm, 1999). The development of bird song is known to depend on highly specific kinds and timing of experience with song in many species (e.g., Nelson, Marler, \& Palleroni, 1995; Nordeen \& Nordeen, 1990; Slater, Eales, \& Clayton, 1988). The studies cited above have demonstrated IEG responses to song in adult birds, but nothing is known about the role of IEGs and other genes in the growth of neural networks that presumably underlie song development in young birds. Given the wealth of information available on song development at both the behavioral and the neural levels, data on genetic involvement in this process could provide an especially complete picture of a developing system from genetic activity to behavioral change.

The response of IEGs to sensory stimulation is only the first step in what must be a very complexly regulated cascade of molecular and cellular events leading to the neural modifications that are finally responsible for developmental changes in behavior (Shaw, Lanius, \& van den Doel, 1994). For example, two of the most intensively studied IEGs, c-fos and c-jun, produce proteins (Fos and Jun, respectively) that link together to form a protein complex (a dimer) before binding to other regions of DNA to further regulate gene activity (Morgan \& Curran, 1989). Studies of the consequences of c-fos and c-jun induction in the hippocampus (e.g., White \& Gall, 1987) have suggested that the preproenkephalin gene may be a target for the products of these IEGs. Preproen-

\footnotetext{
${ }^{1}$ Formulations such as this one also can be interpreted as meaning that a variant form of the gene in question is responsible for the difference between two phenotypic outcomes, in this case the difference between $D$. melanogaster and D. simulans songs. Although accounting for differences in behavior (whether among species or individuals) is a legitimate research enterprise, it is not the same as accounting for the role of genes in the development of behavior, which is our concern in this article; furthermore, it is important to keep terminology and conclusions appropriate to these two endeavors distinct. This point was made very clearly by Lewontin (1974) and has frequently been reiterated, for example, by Oyama (1988) and by Plomin $(1988,1989)$.
} 
kephalin is one of the precursors of endogenous opioids, such as enkephalin, that are involved both in neurogenesis and in various aspects of neural growth and maturation (Hauser, McLaughlin, \& Zagon, 1989; Hauser \& Stiene-Martin, 1992).

Compared with the number and variety of developmental responses to sensory stimulation, there seem to be relatively few IEGs, but Sheng, Lin, and Nelson (1995) have proposed that combinatorial expression of these genes might permit such a variety of responses. Nonetheless, IEG expression is clearly only the first of many steps in the cascade of gene activation that follows sensory stimulation or any other precipitating developmental event. The steps in this cascade are only beginning to be elucidated, but the advent of gene microarray technology seems likely to permit rapid progress in this domain. This technology permits the degree of expression of thousands of genes to be assessed simultaneously, enabling researchers to examine patterns of gene expression in specific tissues and quickly to compare these patterns among organisms that differ in some theoretically interesting way (because they have had different experiences at a particular time during development, for example). Descriptions of the technology are given in articles by Schena (1996), Watson and Akil (1999), and Lockhart and Winzeler (2000). Briefly, the technique involves preparing a glass plate with an array of several thousand fragments of single-stranded DNA, each fragment corresponding to an identified gene from a gene library for the organism under study. mRNA from the tissue in which interesting patterns of gene expression are hypothesized to occur is used to prepare a solution of single-stranded complementary DNA (cDNA), consisting of the DNA sequences corresponding to each mRNA molecule (i.e., the DNA sequences that transcribe the various mRNA molecules during gene expression in the cell). The cDNA is tagged with a fluorescent dye and then applied to the glass plate. Because both the DNA attached to the plate and the cDNA in the solution are single stranded, complementary strands will bind to one another. The plate is then washed and examined under illumination that reveals the fluorescent dye. Bright spots on the plate correspond to DNA sequences from the gene library that have bound significant amounts of cDNA in the solution and therefore identify genes that were expressed in the tissue from which the original mRNA molecules were derived.

Gene microarray technology was used by Lee, Klopp, Weindruch, and Prolla (1999) to identify genes whose expression differs between muscle tissues from young and old mice. They used a library of over 6,000 mouse genes to identify 58 genes whose expression increased with age and another 55 genes whose expression decreased with age. Thus, in a single step, they were able to pinpoint fewer than $2 \%$ of the genes in the library as being somehow involved in the aging process, greatly facilitating continuing investigation of the genetic and molecular mechanisms involved in aging. They also were able to identify a subset of genes whose expression was especially sensitive to the "antiaging" effects of caloric restriction. These results suggest that a similar approach eventually might be used to compare brain tissues from songbirds reared under different conditions of song exposure, for example (if suitable DNA libraries were available), so as to identify the specific genes involved in the various developmental events that take place during song learning.

\section{Conclusion}

Neither genes nor experience shapes behavior directly; instead, each exerts reciprocal effects through the multiple levels of organization that constitute the developing organism. By explicating these various levels and showing where the genes and experience stand in relation to them, the model of behavioral development presented in this article provides a framework that can help researchers both to pose appropriate questions for the analysis of development and to interpret the data that these questions generate. In particular, it incorporates an explicit account of genetic contributions to development that goes beyond metaphorical references to the genes as blueprints or information carriers. By representing genetic activity as a molecular event, occurring within the nuclei of cells in neural and nonneural tissues, the model emphasizes the analytical and explanatory distances between the genes and behavior. Insisting that researchers speak of the genes and their contributions to behavior in the language of molecular and cellular biology rather than that of psychology helps to instill the realization that it is the molecular level of analysis at which genes actually have their immediate effects, with subsequent influences being mediated through multiple levels of organization. Any complete account of behavioral development must include an explication of genetic contributions, but such an account cannot usefully be provided by terminology in which genes are said to encode or specify behavior (Johnston, 1987, 1988; Nijhout, 1990; Oyama, 2000; Schaffner, 1998; see Mahner \& Bunge, 1997, chapter 8).

\section{References}

Anokhin, K. V., Mileusnic, R., Shamakina, I. Y., \& Rose, S. P. R. (1991). Effects of early experience on c-fos gene expression in the chick forebrain. Brain Research, 544, 101-107.

Arenander, A. T., \& Herschman, H. R. (1993). Primary response gene expression in the nervous system. In S. E. Loughlin \& J. H. Fallon (Eds.), Neurotrophic factors (pp. 89-128). San Diego, CA: Academic Press.

Arnold, A. P., \& Breedlove, S. M. (1985). Organizational and activational effects of sex steroids on brain and behavior: A reanalysis. Hormones and Behavior, 19, 469-498.

Bateson, P. (1983). Genes, environment and the development of behaviour. In T. H. Halliday \& P. J. B. Slater (Eds.), Animal behaviour: Vol. 3. Genes, development and learning (pp. 52-81). Oxford, England: Blackwell.

Bateson, P. (1987). Biological approaches to the study of behavioural development. International Journal of Behavioral Development, 10, $1-22$.

Bateson, P. (1996). Design for a life. In D. Magnusson (Ed.), The lifespan development of individuals: Behavioral, neurobiological, and psychosocial perspectives (pp. 1-20). Cambridge, England: Cambridge University Press.

Bateson, P., \& Martin, P. (2000). Design for a life: How behavior and personality develop. New York: Simon \& Schuster.

Brennan, P. A., Hancock, D., \& Keverne, E. B. (1992). The expression of the immediate-early genes c-fos, egr-1, and c-jun in the accessory olfactory bulb during the formation of an olfactory memory in mice. Neuroscience, 49, 277-284.

Buss, D. M. (1994). The evolution of desire: Strategies of human mating. New York: Basic Books.

Chalfie, M. (1993). Touch receptor development and function in Caenorhabditis elegans. Journal of Neurobiology, 24, 1433-1441.

Collaer, M. L., \& Hines, M. (1995). Human behavioral sex differences: A 
role for gonadal hormones during early development? Psychological Bulletin, 118, 55-107.

Dragunow, M. (1996). A role for immediate-early transcription factors in learning and memory. Behavior Genetics, 26, 293-299.

Ehret, G., \& Fischer, R. (1991). Neuronal activity and tonotopy in the auditory system visualized by c-fos gene expression. Brain Research, 567, 350-354.

Gottlieb, G. (1976). The roles of experience in the development of behavior and the nervous system. In G. Gottlieb (Ed.), Studies on the development of behavior and the nervous system: Vol. 3. Neural and behavioral specificity (pp. 25-54). New York: Academic Press.

Gottlieb, G. (1991). Experiential canalization of behavioral development: Theory. Developmental Psychology, 27, 4-13.

Gottlieb, G. (1995). Some conceptual deficiencies in "developmental" behavior genetics. Human Development, 38, 131-141.

Gottlieb, G. (1996). A systems view of psychobiological development. In D. Magnusson (Ed.), The lifespan development of individuals: Behavioral, neurobiological, and psychosocial perspectives (pp. 76-103). Cambridge, England: Cambridge University Press.

Gottlieb, G. (1998). Normally occurring environmental and behavioral influences on gene activity: From central dogma to probabilistic epigenesis. Psychological Review, 105, 792-802.

Gray, R. D. (1992). Death of the gene: Developmental systems strike back. In P. E. Griffiths (Ed.), Trees of life: Essays in philosophy of biology (pp. 165-209). Dordrecht, The Netherlands: Kluwer.

Griffiths, P. E., \& Gray, R. D. (1994). Developmental systems and evolutionary explanation. Journal of Philosophy, 91, 277-305.

Hall, J. C. (1998). Genetics of biological rhythms in Drosophila. Advances in Genetics, 38, 135-184.

Hauser, K. F., McLaughlin, P. J., \& Zagon, I. S. (1989). Endogenous opioid systems and the regulation of dendritic growth and spine formation. Journal of Comparative Neurology, 281, 13-22.

Hauser, K. F., \& Stiene-Martin, A. (1992). Opiates and the regulation of nervous system development: Evidence from in vitro studies. In R. P. Hammer (Ed.), Neurobiology of opiates (pp. 23-61). Boca Raton, FL: CRC Press.

Jin, H., \& Clayton, D. F. (1997). Localized changes in immediate-early gene regulation during sensory and motor learning in zebra finches. Neuron, 19, 1049-1059.

Johnston, T. D. (1987). The persistence of dichotomies in the study of behavioral development. Developmental Review, 7, 149-182.

Johnston, T. D. (1988). Developmental explanation and the ontogeny of birdsong: Nature/nurture redux. Behavioral and Brain Sciences, 11, 617-663.

Keller, E. F. (1994). Language and science: Genetics, embryology, and the discourse of gene action. Great Ideas Today, 1994, 23-29.

Kimpo, R. R., \& Doupe, A. J. (1997). FOS is induced by singing in distinct neuronal populations in a motor network. Neuron, 18, 315-325.

Lanahan, A., \& Worley, P. (1998). Immediate-early genes and synaptic function. Neurobiology of Learning \& Memory, 70, 37-43.

Lander, E. S., \& Weinberg, R. A. (2000). Genomics: Journey to the center of biology. Science, 287, 1777-1782.

Lee, C.-K., Klopp, R. G., Weindruch, R., \& Prolla, T. A. (1999). Gene expression profile of aging and its retardation by caloric restriction. Science, 285, 1390-1393.

Lewontin, R. C. (1974). The analysis of variation and the analysis of causes. American Journal of Human Genetics, 26, 400-411.

Lloyd, E. A. (1999). Evolutionary psychology: The burdens of proof. Biology and Philosophy, 14, 211-233.

Lockhart, D. J., \& Winzeler, E. A. (2000). Genomics, gene expression and DNA arrays. Nature, 405, 827-836.

Mahner, M., \& Bunge, M. (1997). Foundations of biophilosophy. Berlin: Springer.

Marler, P. (1990). Song learning: The interface between behaviour and neuroethology. Philosophical Transactions of the Royal Society of London B, 329, 109-114.

McClearn, G. E., Plomin, R., Gora-Maslak, G., \& Crabbe, J. C. (1991). The gene chase in behavioral science. Psychological Science, 2, 222-229.

Mello, C., Nottebohm, F., \& Clayton, D. (1995). Repeated exposure to one song leads to a rapid and persistent decline in an immediate early gene's response to that song in zebra finch telencephalon. Journal of Neuroscience, 15, 6919-6925.

Mello, C. V., Vicario, D. S., \& Clayton, D. F. (1992). Song presentation induces gene expression in the songbird forebrain. Proceedings of the National Academy of Sciences, 89, 6818-6822.

Morgan, J. I., \& Curran, T. (1989). Stimulus-transcription coupling in neurons: Role of cellular immediate-early genes. Trends in Neuroscience, 12, 459-462.

Morgan, J. I., \& Curran, T. (1991). Stimulus-transcription coupling in the nervous system: Involvement of the inducible protooncogenes fos and jun. Annual Review of Neuroscience, 14, 421-451.

Nastiuk, K. L., Mello, C. V., George, J. M., \& Clayton, D. F. (1994). Immediate-early gene responses in the avian song control system: Cloning and expression analysis of the canary c-jun cDNA. Molecular Brain Research, 27, 299-309.

Nelkin, D., \& Lindee, M. S. (1995). The DNA mystique: The gene as a cultural icon. New York: Freeman.

Nelson, D. A., Marler, P., \& Palleroni, A. (1995). A comparative approach to vocal learning: Intraspecific variation in the learning process. Animal Behaviour, 50, 83-97.

Nijhout, H. F. (1990). Metaphors and the role of genes in development. BioEssays, 12, 441-446.

Nordeen, E. J., \& Nordeen, K. W. (1990). Neurogenesis and sensitive periods in avian song learning. Trends in Neurosciences, 13, 31-36.

Nottebohm, F. (1989). From birdsong to neurogenesis. Scientific American, 260(2), 74-79.

Oyama, S. (1985). The ontogeny of information: Developmental systems and evolution. Cambridge, England: Cambridge University Press.

Oyama, S. (1988). Populations and phenotypes: A review of Development, Genetics, and Psychology, by R. Plomin. Developmental Psychobiology, 21, 101-105.

Oyama, S. (2000). The ontogeny of information: Developmental systems and evolution (2nd ed., revised and expanded). Durham, NC: Duke University Press.

Pfaff, D. W. (1997). Hormones, genes, and behavior. Proceedings of the National Academy of Sciences, 94, 14213-14216.

Plomin, R. (1988). A stake in the heart: A review of The Ontogeny of Information, by S. Oyama. Developmental Psychobiology, 21, 93-95.

Plomin, R. (1989). Environment and genes: Determinants of behavior. American Psychologist, 44, 105-111.

Plomin, R., \& Rutter, M. (1998). Child development, molecular genetics, and what to do with genes once they are found. Child Development, 69 , 1223-1242.

Rivkees, S. A., Weaver, D. R., \& Reppert, S. M. (1992). Circadian and developmental regulation of $O c t-2$ gene expression in the suprachiasmatic nuclei. Brain Research, 598, 332-336.

Robertson, H. A. (1992). Immediate-early genes, neuronal plasticity, and memory. Biochemistry and Cell Biology, 70, 729-737.

Rouiller, E. M., Wan, X. S. T., Moret, V., \& Liang, F. (1992). Mapping of c-fos expression elicited by pure tone stimulation in the auditory pathways of the rat, with emphasis on the cochlear nucleus. Neuroscience Letters, 144, 19-24.

Rusak, B., Robertson, H. A., Wisden, W., \& Hunt, S. P. (1990). Light pulses that shift rhythms induce gene expression in the suprachiasmatic nucleus. Science, 248, 1237-1240.

Schaffner, K. F. (1998). Genes, behavior, and developmental emergentism: One process, indivisible? Philosophy of Science, 65, 209-252. 
Schena, M. (1996). Genome analysis with gene expression microarrays. BioEssays, 18, 427-431.

Shaw, C. A., Lanius, R. A., \& van den Doel, K. (1994). The origin of synaptic neuroplasticity: Crucial molecules or a dynamical cascade? Brain Research Reviews, 19, 241-263.

Sheng, H. Z., Lin, P. X., \& Nelson, P. G. (1995). Combinatorial expression of immediate early genes in single neurons. Molecular Brain Research, 30, 196-202.

Slater, P. J. B., Eales, L. A., \& Clayton, N. S. (1988). Song learning in zebra finches (Taeniopygia guttata): Progress and prospects. Advances in the Study of Behavior, 18, 1-34.

Thelen, E. (1995). Motor development: A new synthesis. American Psychologist, 50, 79-95.

Thelen, E., Kelso, J. A. S., \& Fogel, A. (1987). Self-organizing systems and infant motor development. Developmental Review, 7, 39-65.

Tischmeyer, W., \& Grimm, R. (1999). Activation of immediate early genes and memory formation. Cellular and Molecular Life Sciences, 55, 564-574.

Turkheimer, E. (1998). Heritability and biological explanation. Psychological Review, 105, 782-791.

Wahlsten, D. (1999). Single-gene influences on brain and behavior. Annual Review of Psychology, 50, 599-624.
Watson, A. J., \& Akil, H. (1999). Gene chips and arrays revealed: A primer on their power and their uses. Biological Psychiatry, 45, 533-543.

Wheeler, D. A., Kyriacou, C. P., Greenacre, M. L., Yu, Q., Rutila, J. E., Rosbash, M., \& Hall, J. C. (1991). Molecular transfer of a speciesspecific behavior from Drosophila simulans to Drosophila melanogaster. Science, 251, 1082-1085.

White, J. D., \& Gall, C. M. (1987). Differential regulation of neuropeptide and proto-oncogene mRNA content in the hippocampus following recurrent seizures. Molecular Brain Research, 3, 21-29.

Williams, S., Evan, G. I., \& Hunt, S. P. (1990). Changing patterns of c-fos induction in spinal neurons following thermal cutaneous stimulation in the rat. Neuroscience, 36, 73-81.

Worley, P. F., Cole, A. J., Murphy, T. H., Christy, B. A., Nakabeppu, Y., \& Baraban, J. M. (1990). Synaptic regulation of immediate-early genes in brain. Cold Spring Harbor Symposia on Quantitative Biology, 55, 213-223.

Received June 7, 2000

Accepted November 29, 2000

\section{Low Publication Prices for APA Members and Affiliates}

Keeping you up-to-date. All APA Fellows, Members, Associates, and Student Affiliates receive-as part of their annual dues-subscriptions to the American Psychologist and APA Monitor. High School Teacher and International Affiliates receive subscriptions to the APA Monitor, and they may subscribe to the American Psychologist at a significantly reduced rate. In addition, all Members and Student Affiliates are eligible for savings of up to $60 \%$ (plus a journal credit) on all other APA journals, as well as significant discounts on subscriptions from cooperating societies and publishers (e.g., the American Association for Counseling and Development, Academic Press, and Human Sciences Press).

Essential resources. APA members and affiliates receive special rates for purchases of APA books, including the Publication Manual of the American Psychological Association, and on dozens of new topical books each year.

Other benefits of membership. Membership in APA also provides eligibility for competitive insurance plans, continuing education programs, reduced APA convention fees, and specialty divisions.

More information. Write to American Psychological Association, Membership Services, 750 First Street, NE, Washington, DC 20002-4242. 